This article has been scanned by iThenticat No plagiarism detected

Volume 3, Issue 6, December 2021

p. $418-428$

\title{
PUBLIC SPENDING ON EDUCATION AND ITS ROLE IN PROMOTING ECONOMIC GROWTH -SINGAPORE IS A MODEL-
}

http://dx.doi.org/10.47832/2757-5403.6-3.30

\section{Amneh ZAHRAN 1}

\begin{abstract}
:
This Study attempts to demonstrate the importance of public spending on education in supporting economic growth, in light of the accelerating knowledge and technological development, and to shed light on the bilateral relationship between public spending on education and economic growth, by addressing Singapore's experience in this field for the years (2009-2019). With a comparison, , to the situation of the education sector in the Arab countries and the amount of spending on it. The study used the descriptive analytical method and was based on the analysis of statistics, data and reports emanating from the World Bank and the Organization for Economic and Development. Singapore's experience can be considered a pioneering experience in investing human capital through training it in various educational stages and finding a place for every student, regardless of their capabilities, in order to advance society despite the scarcity of natural resources.

Through this perspective, some recommendations can be put forward that contribute to supporting economic growth in the Arab countries: Studying the needs of the labor market. Emphasizing the importance of technical education and encouraging students to join it. Providing qualified educational cadres capable of identifying students' needs and providing them with the skills and knowledge that will enable them to adapt to the rapid changes.
\end{abstract}

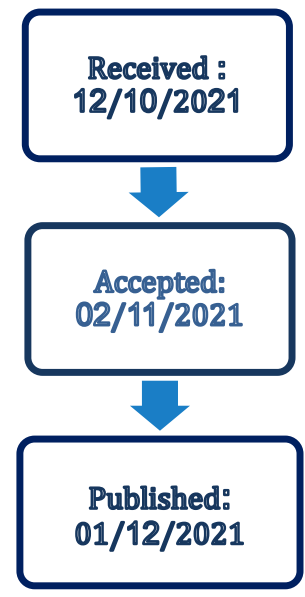

Key words: Public Spending, Economic, The Growth.

\footnotetext{
${ }^{1}$ Researcher, Arab American University, Palestine, amnehzahran34@gmail.com, https://orcid.org/0000-001$\underline{5671-6794}$
}

Copyright $(\odot$ Published by IJHER Journal, www. ijherjournal. com Rimar Academy, Fatih, Istanbul, 34093 Turkey

All rights reserved 


\title{
الإنفاق العام على التعليم ودوره في تعزيز النمو الاثتصادي

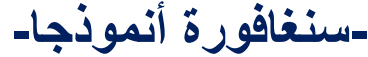

\author{
2
}

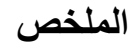

تُحاول هذه الدراسة بيان أهمية الإنفاق العام على التعليم في دعم النمو الاقتصادي، في ظل التل

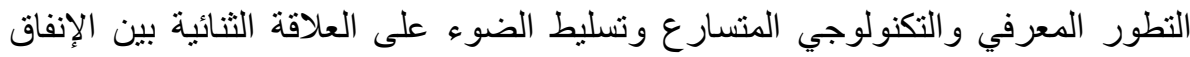

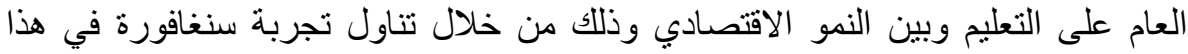

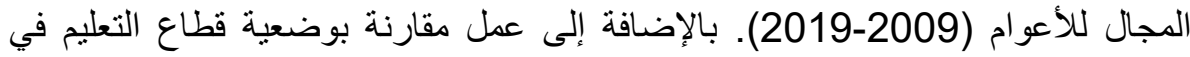

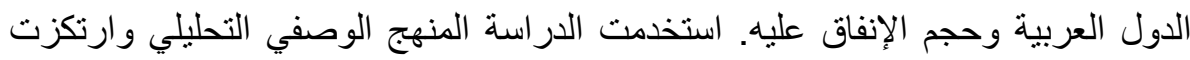

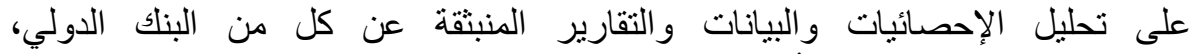

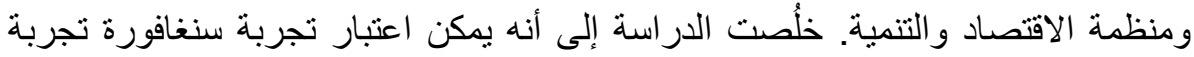

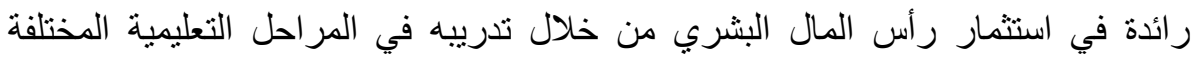

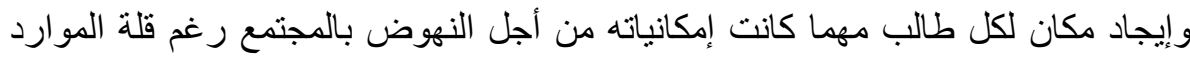

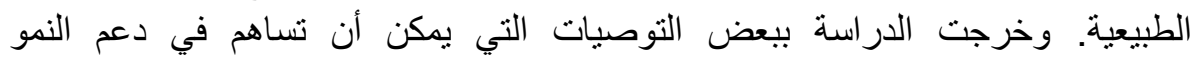
الاقتصادي في الدول العربية : دراسة احتياجات سوق العمل. التأكيد على أهمية التعليم

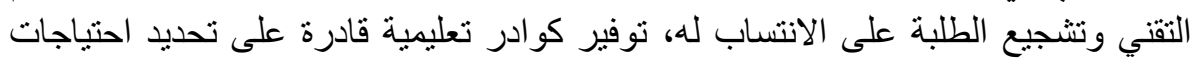

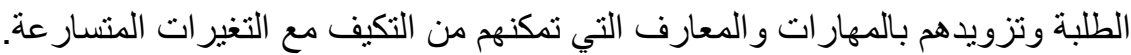
الكلمات المفتاحية: الإنفاق العام، النمو، الاقتصاد.
\end{abstract}

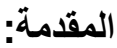

يُعد التعليم من القطاعات التي حَظيت بالاهتمام من قبل العديد من الدول التي اعتبرت أن الاستثمار في هذا القطاع مصدراً

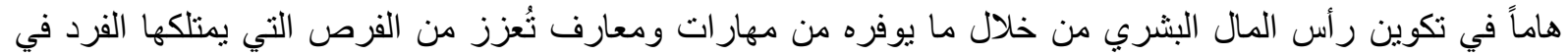

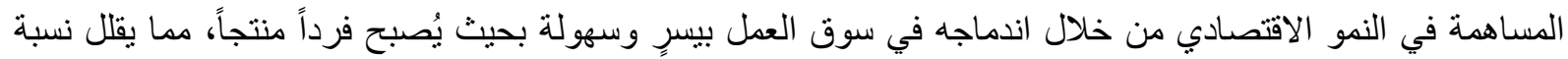

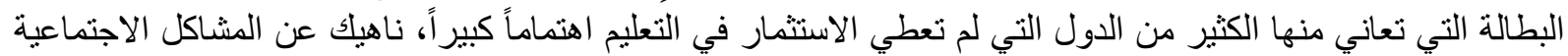

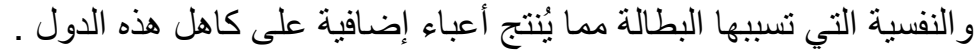

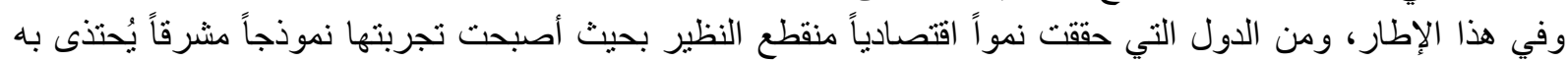
نجد سنغافورة في المقدمة بعد أن كانت مستعمرة بريطانية في القرن التاسع عشر وانتقلت اللى الحكم الذاتي عام 1959

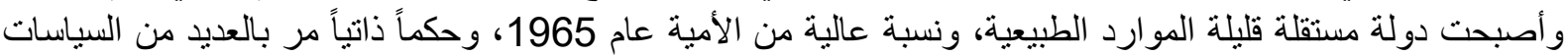

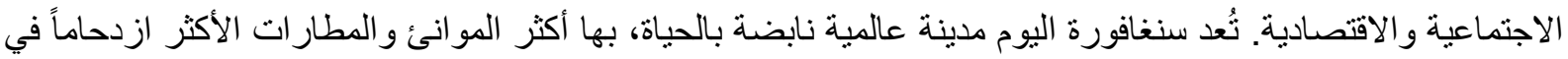

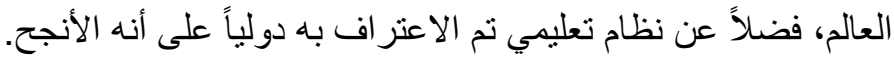

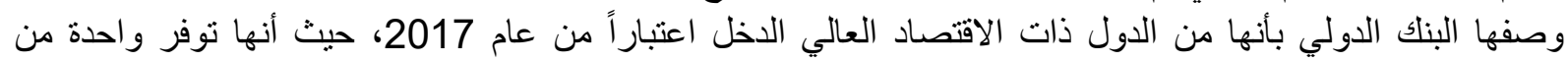

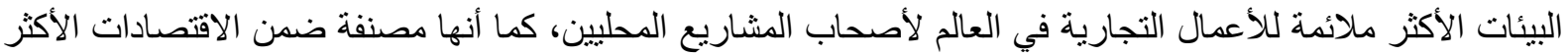

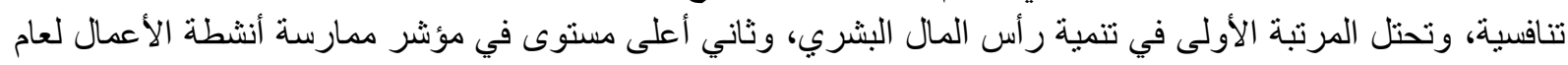
.2018 و أنـارت اليونسكو في أحد تقارير ها، أن الهدف من نظام التعليم في سنغافورة رعاية كل طفل، ومساعدة جميع الطلاب

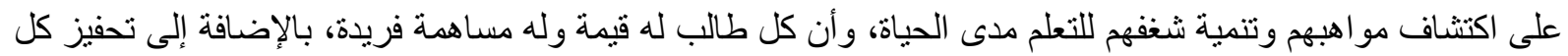

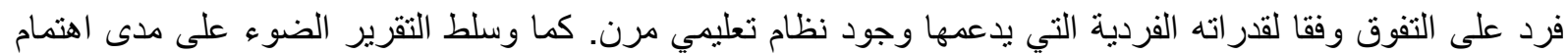

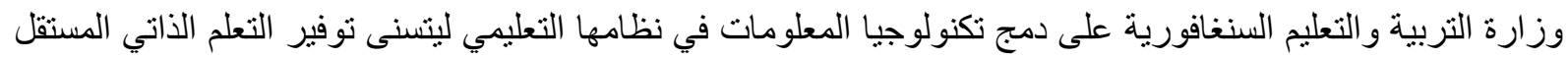
وتوسيع آفاق المُنَعلم بالإضافة إلى تزويد الطلاب بالمهارات التطبيقية والمعرفية من أجل إعدادهم بشكلٍ أفضل لتحديات 


\section{PUBLIC SPENDING ON EDUCATION AND ITS ROLE IN PROMOTING \\ ECONOMIC GROWTH -SINGAPORE IS A MODEL-}

الغد المتنوعة. ويعتمد النظام التعليمي بشكل أساسي على الإدراك المبكر لمدى أهمية تطوير الثروة البشرية ومدى تأثثر ذلك على التقدم الاقتصادي. (داود، 2017)

الاراسات السابقة

تناولت الأدبيات الاقتصادية الاستثمار في التعليم كعامل رئيسي في تعزيز النمو الاقتصادي. حيث تم الإشارة إليه على أنه الإنه

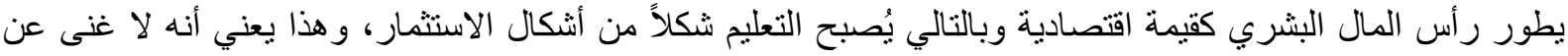

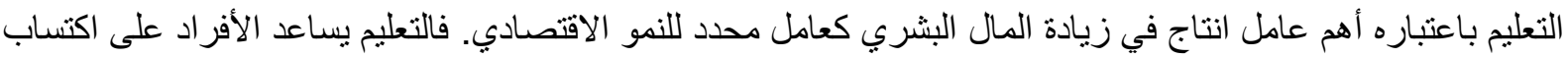

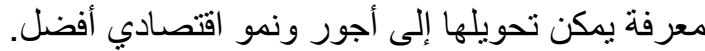
أجرى وانج وشاشا دراسة (Shasha،Wang2016) حيث قاما بيناء نموذج بيانات للتحقيق في تأثير رأس المال

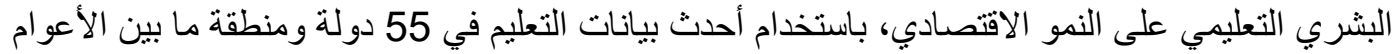

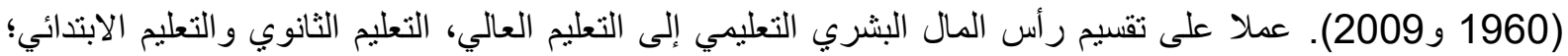

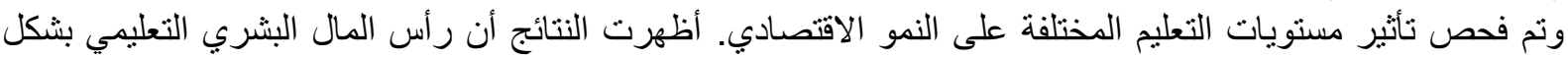

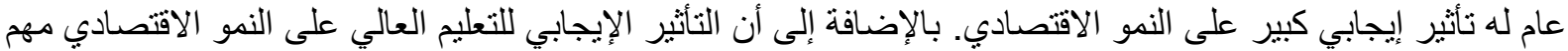

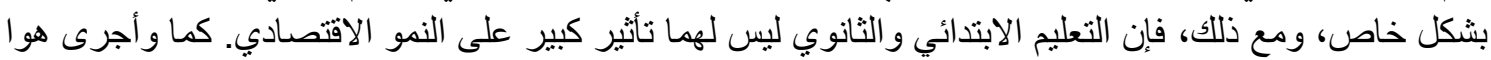
(2016, Hui)

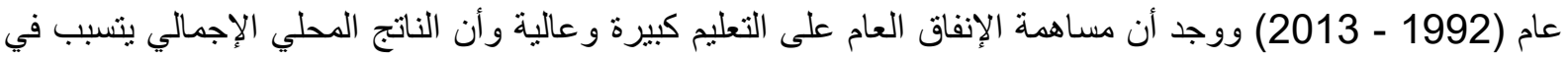

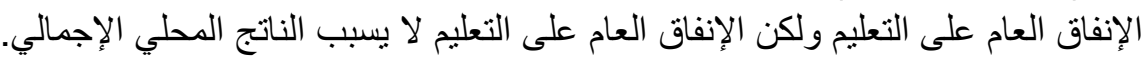
وكانت هنالك دراسة ماسابي وبادودا Mussayy and Babatude,

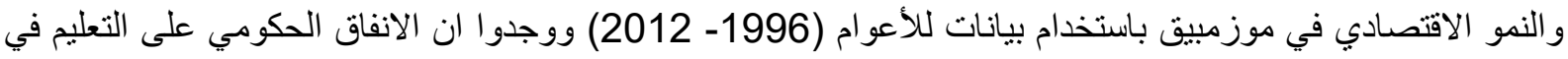

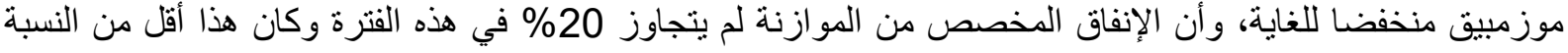

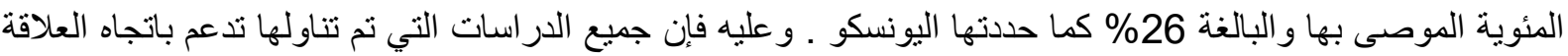
الإيجابية بين الانفاق العام و النمو الاقتصادي. ومن هذا المنطلق تحاول هذه الورقة البحثية تسليط الضوء على الإنفاق الإن العان العام على التعليم وأهميته في تحقيق النمو

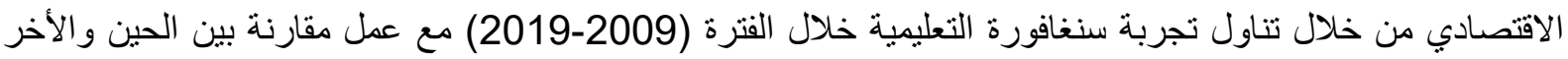

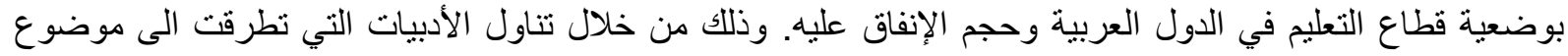

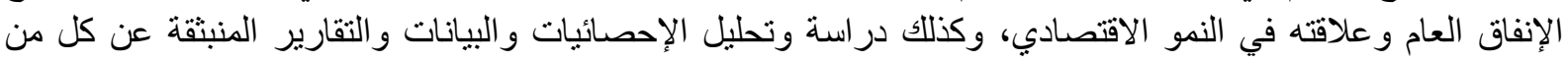

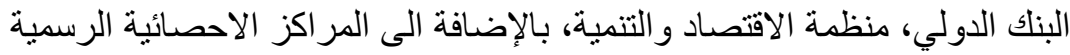
و عليه، تتمثل إنكالية الدراسة على النحو الآتي:

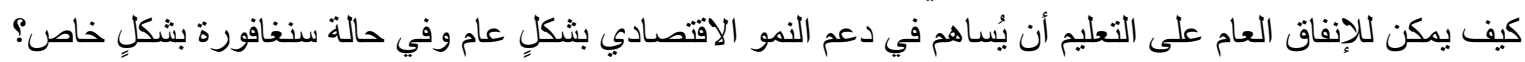

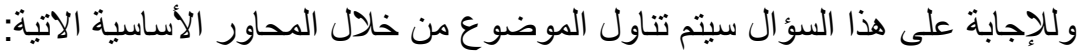
ـ ـ علاقة الإنفاق العام على التعليم و النمو الاقتصادي. - دور الإنفاق العام على التعليم في دعم النمو الاقتصادي النعامي تجربة سنغافورة.

علاقة الإنفاق العام على التعليم والنمو الاقتصادي

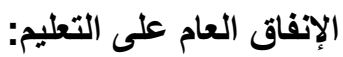

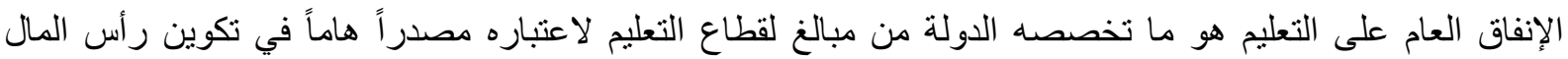

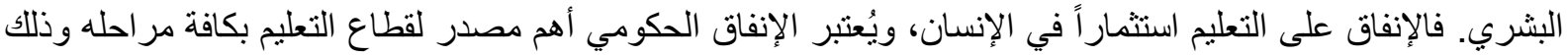

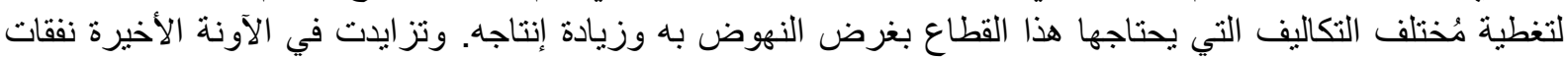

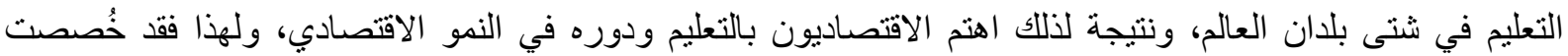

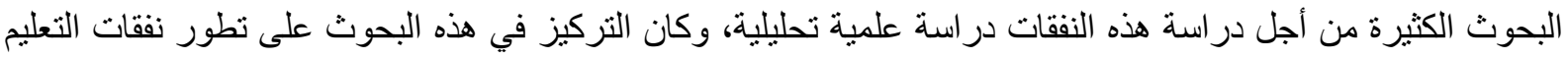

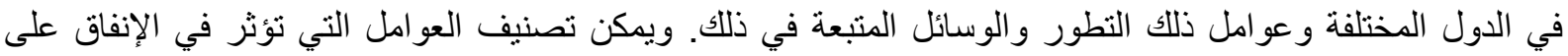
التعليم إلى عو امل داخلية وأخرى خارجية كما جاءت في الرشدان (2001) 


\section{العوامل الااخلية ذات علاقة بالمؤسسات التعليمية فقد جاءت على النحو الآتي: • - مستوى أجور العاملين بالمؤسسات التعليمية. • التوزيع العمري لهيئات التعليه.

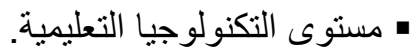 • منصاب المعلم من ساعات التدريس. • ارتفاع حجم الإهدار و الذي ترجع غاع التربن غالبيته إلى زيادة نسب التسرب و الرسوب.}

أما العوامل الخارجية والتي لا ترتبط بالمؤسسات التعليمية مباشرة فهي: • المستوى العام للاخل القومي: فكلما ارتفع الدخل القومي للمجتمع زاد دخل الأفراد بالتالي فان ذللك يؤدي إلى زيادة • مستوى نفقات المعيشة: حيث النهات كلما ارتفعت أسعار السلع والخدمات زادت نفقات المعيشة وبالتالي نفقات الإنفاق التعليمي. • المستوى التكنولوجي العام في المجتمع: ارتفاع مستوى التكنولوجيا يؤثر على ارتفاع الإنفاق التعليمي.

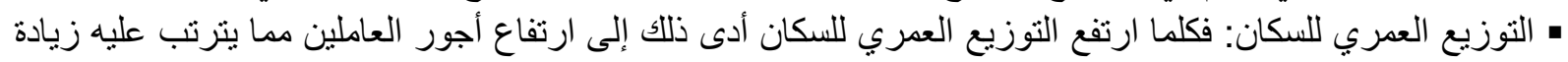
الإنفاق على التربية والتعليح.

\section{التعليم والتنمية الاقتصادية}

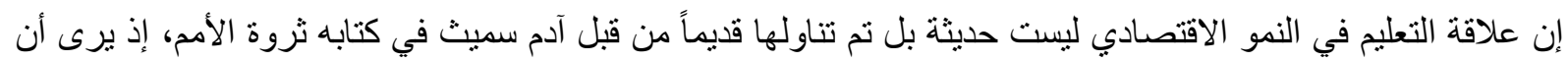

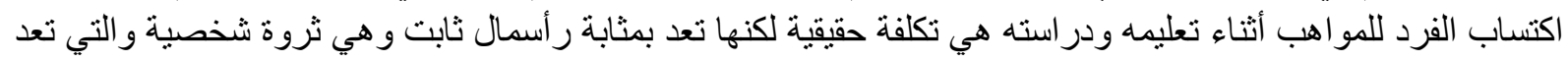

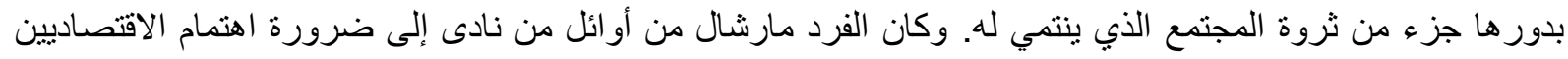

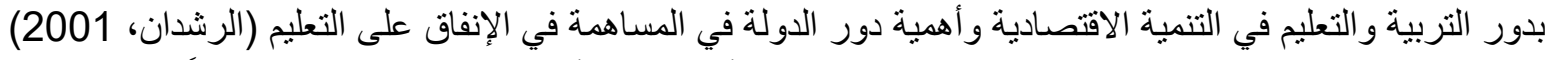

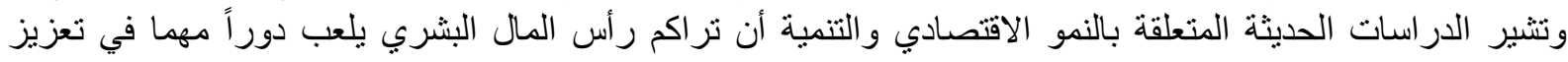

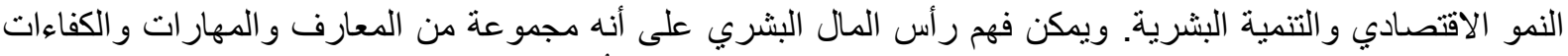

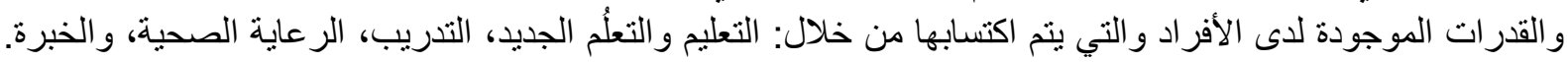

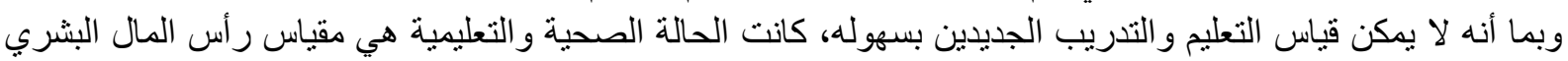

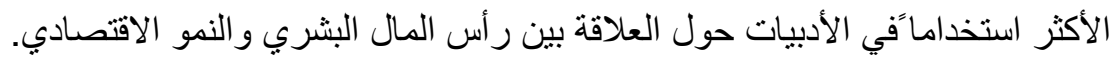

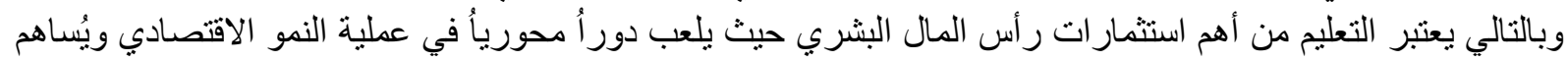

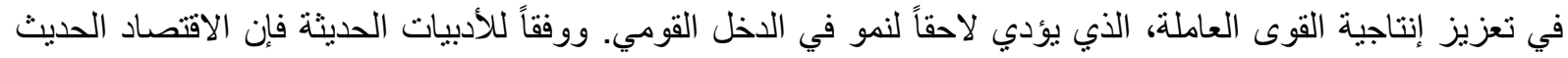

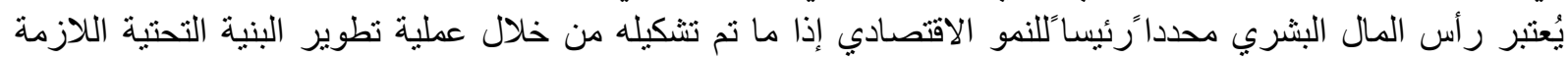
للتعليم المدرسي القائم على تنمية المهار ات. (Shufade,De 2020) وفي دراسة قام بها والش (walsh) كما جاء في الرشدان 2001 حول الاستثمار في التعليم العالي ليتحقق من عائداته

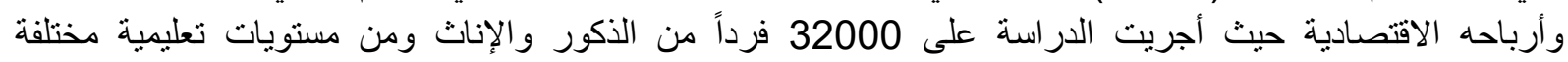
واختصاصات متتو عة . خلص الى النتائج الآتية:

أولاً: إن القدرات التي يحصل عليها الأفراد عن طريق التعليم الجامعي والإعداد المهني هي نوع من راس المال له ثمن

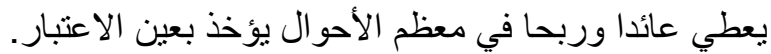

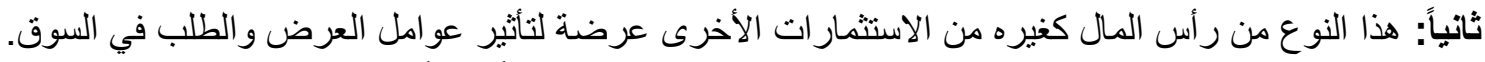

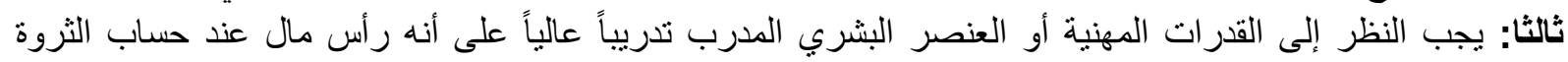
القومية للمجتمع. و هذا يعني أن نظرية رأس المال تنطبق على الإنسان أيضا. ويمكن القول أن نجاح التعليم يكمن في مدى قدرته على الاستجابة لمتطلبات الاقتصاد في بلد ما ومدى استتماره في الأيدي الإي الإني

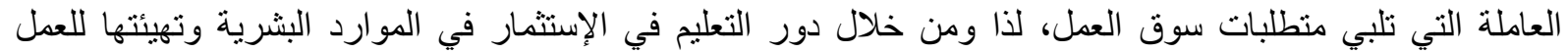
و الإنتاج نظهر العلاقة بين النظام التعليمي والاقتصاد القومي ويمكن توضيح هذه العلاقة من خلال الثكل الآتي: 


\section{PUBLIC SPENDING ON EDUCATION AND ITS ROLE IN PROMOTING \\ ECONOMIC GROWTH -SINGAPORE IS A MODEL-}

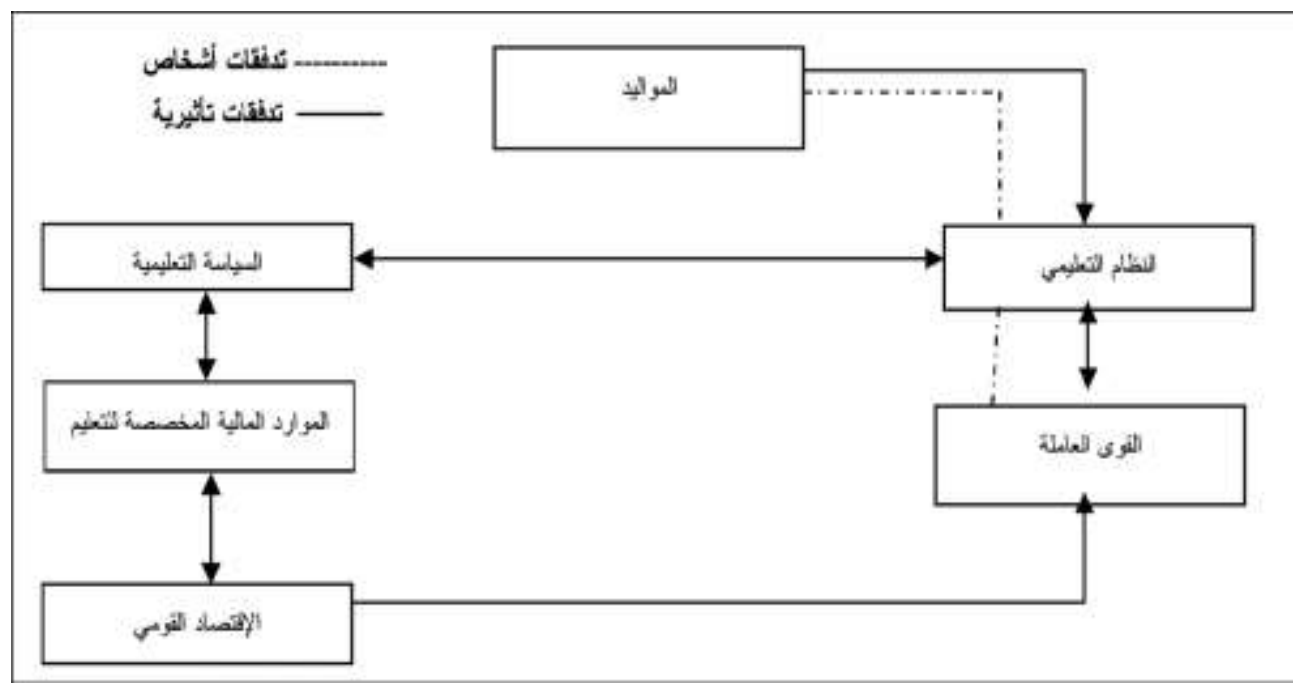

المصدر: العارية، حسين (2012)

نلاحظ أن هنالك تدفقات تأثيرية و أخرى بشرية ويتضح وجود علاقة تبادلية بين الاقتصاد و النظام التعليمي، وذللك من خلال

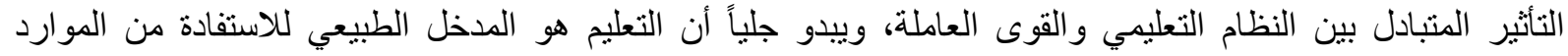

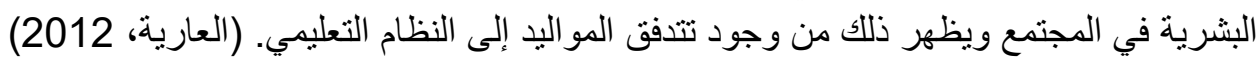
ويمكن تتاول أهم العوامل التي دفعت الاقتصاديين إلى الاهتمام بالتعليم على النحو النحو الآتي:

• إدر الك الدول النامية المنز ايد لأهمية التعليم ودوره المتميز في تحقيق التنمية الاقتصادية.

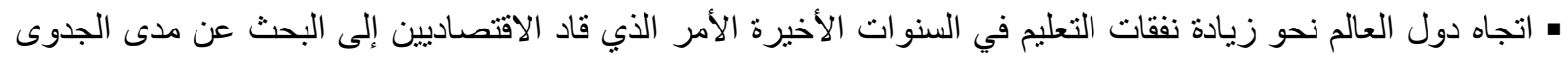

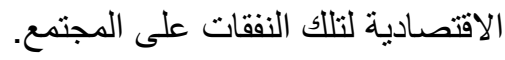
• عجز غالبية البلدان في مواجهة أعبائها التعليمية أمام تزايد أعداد الطلاب وظهور الحاجة الىى دراسة تكاليف التعليم

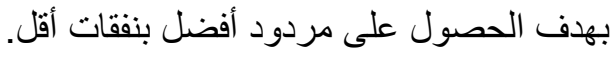

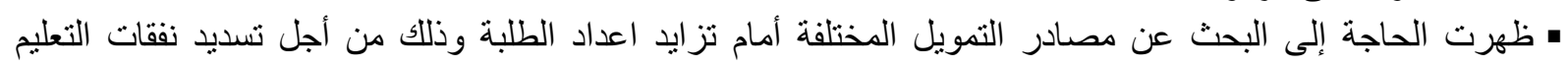

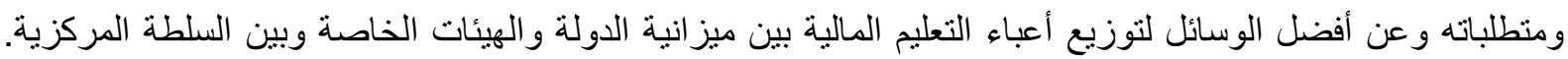

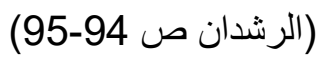
• وفي السياق نفسه لا بد من الإشارة الى الى الأسباب التي دعت الاقتصاديين من اعتبار أن الاستثمار في التعليم مثررا لرؤوس الأموال و إلى إبراز دور ها في التنمية الاقتصادية:

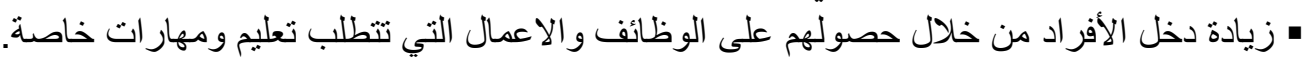

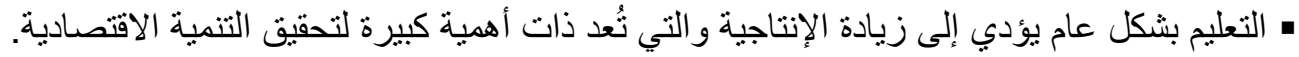

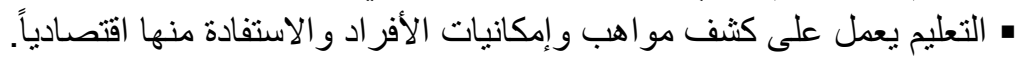

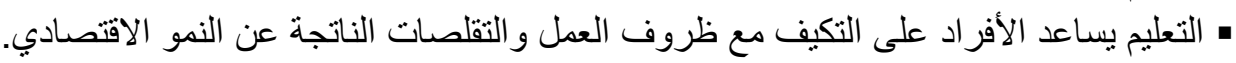

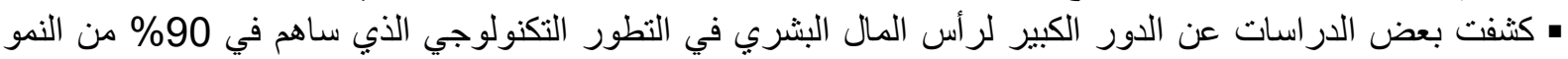

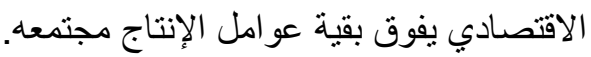
• التعليم هو أحد أقوى الوسائل التي يستعان بها للحد من الفقر وعدم الإنصاف ويعتبر أساسا للنمو الاقتصادي المستدام. (العادلي، 2013)

دور الإنفاق على التعليم في دعم النمو الاقتصادي (سنغافورة انموذجا) من بين الأنظمة التعليمية الاسيوية تبرز سنغافورة لأدائها الأكاديمي المثتاز في التقييمات الدولية. وكان آخر إنجاز التهاتها

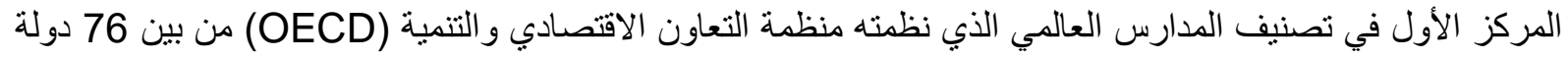

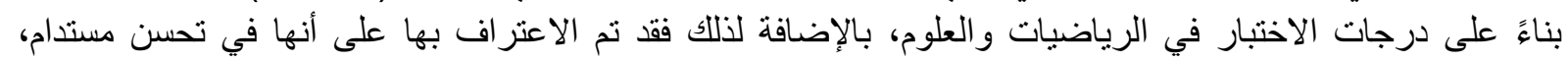
ووصفت بأنها عظيمة في تقرير ماكنزي 2010. 


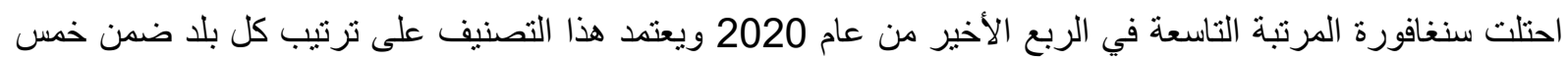

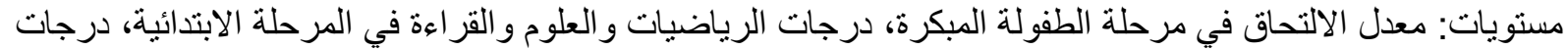

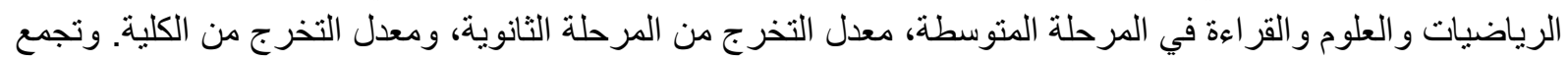

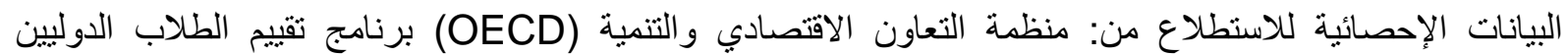

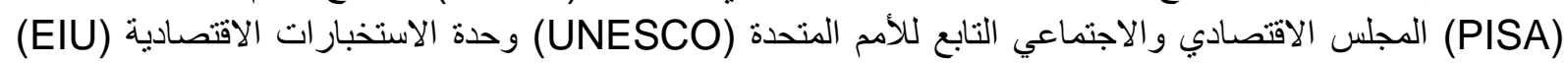
الاتجاهات في دراسة الرياضيات و العلوم الدولية (TIMS)

https://worldtop20. org/worldbesteducationsystem

إن أهم مورد لسنغافورة هو شعبها بسبب نقص الأراضي والموارد، فكانت التحسينات والاستثمارات في نظام التعليم

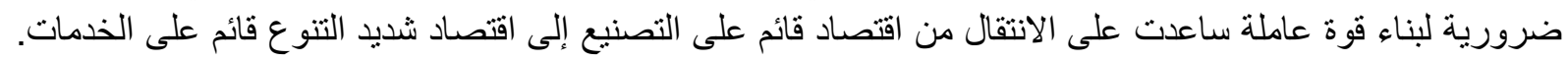

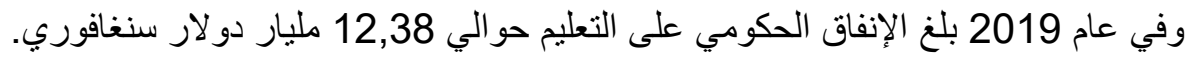

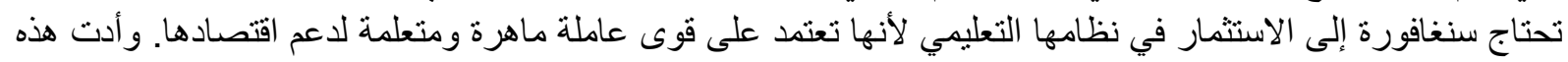

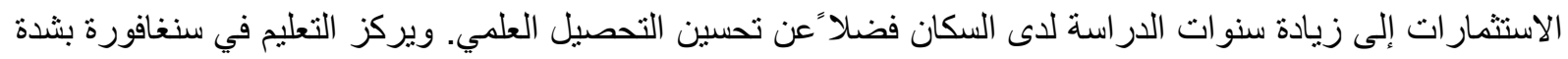

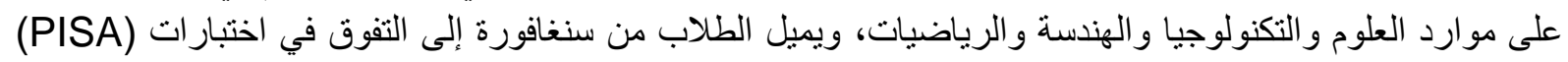

https://www. statista. com

$$
\text { في العلوم و الرياضيات. }
$$

التطورات والمراحل التعليمية التي مرت بها سنغافورة:

من أجل فهم النظام التعليمي في سنغافورة لا بد من ملاحظة وجود ثلاث مر احل إصلاحية مرت بها الدولة منذ استقلالها: (2016, Tana)

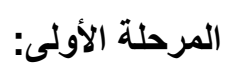
تخريج عمال مدربين في السنوات الأولى وذلك من أجل إيجاد عدد كافٍ من العمال المهرة من أجل اقتصاد موجه للتصدير ، ومن أجل تحقيق هذا الهدف نم التركيز على التعليم المهني و الفني التطبيقي.

المرحلة الثانية:1966 -1997

سياسة ثنائية اللغة وذلك باعتبار اللغة الإنجليزية اللغة الأولى واللغة الأم هي اللغة الثانية. واهتم النظام التعليمي باللغة

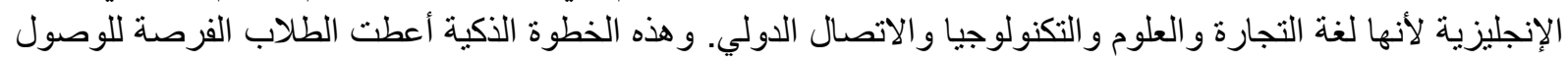

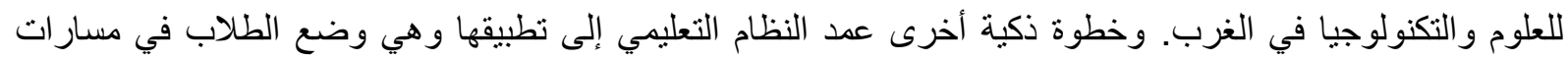

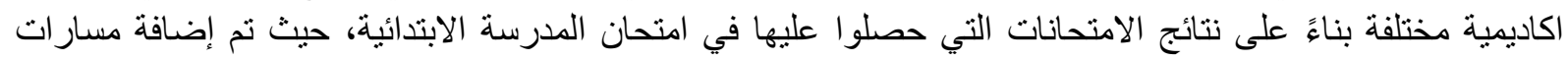

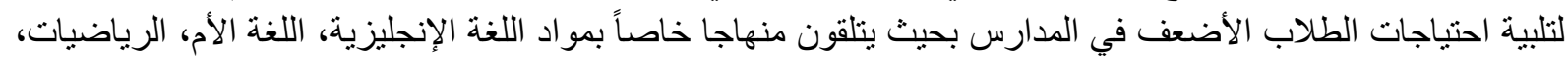

تقنيات الكمبيوتر و الدر اسات التقنية التي يتم تدريسها على مستو الهم ويلتحقون بعد ذللك بالمعاهد المهنية.

المرحلة الأخيرة والحالية: 1997- لغاية الان

انطلقت هذه المرحلة من إطار رؤية مدارس التفكير التي تطمح إلى تطوير التفكير الإبداعي وترسيخ الثغف الدائم للتعلم. ويرتكز هذا النوع من التعليم على أن جميع المواهب اهب والقدرات لهات لها نفس القيمة وسيتم رعايتها بشكل منساوٍ ويتم تنميتها لاى جميع الطلاب بناء على اهنماماتهم و إمكانياتهر.

تقييم النظام التعليمي في سنغافورة:

غالباً ما تظهر جودة التعليم كقضية مركزية للنقاش السياسي والأكاديمي حول كيفية إصلاح أنظمة التعليم للتعامل بشكل

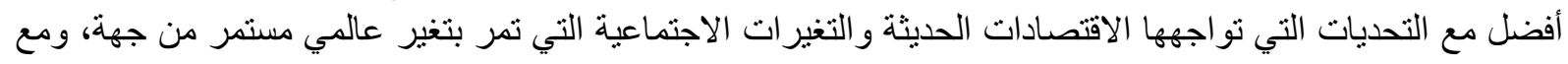

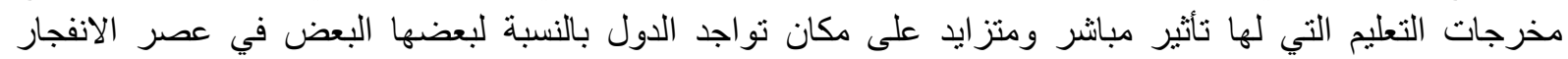
المعرفي. ويعتبر اختبار (PISA) أحد الاختبارات العالمية التي يتم بموجبها تقييم كفاءة الأنظمة التعليمية في كافة دول 


\section{PUBLIC SPENDING ON EDUCATION AND ITS ROLE IN PROMOTING \\ ECONOMIC GROWTH -SINGAPORE IS A MODEL-}

العالم. والذي يركز على معرفة القراءة والكتابة والحساب و العلوم. تستخدم نتائجه كأداة للتغيير في السياسات التعليمية

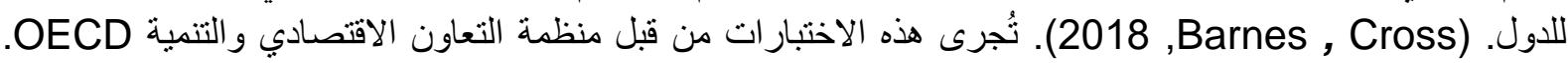

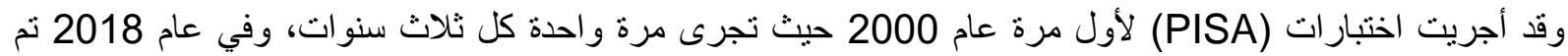
تطبيق الاختبار على حو الي 80 دولة لقياس قدرات الطلبة ذوي 15 عاما في مجالات القراءة التاة والريات الرياضيات و العلوم من https://nces. ed.gov

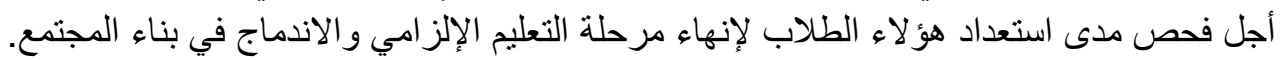

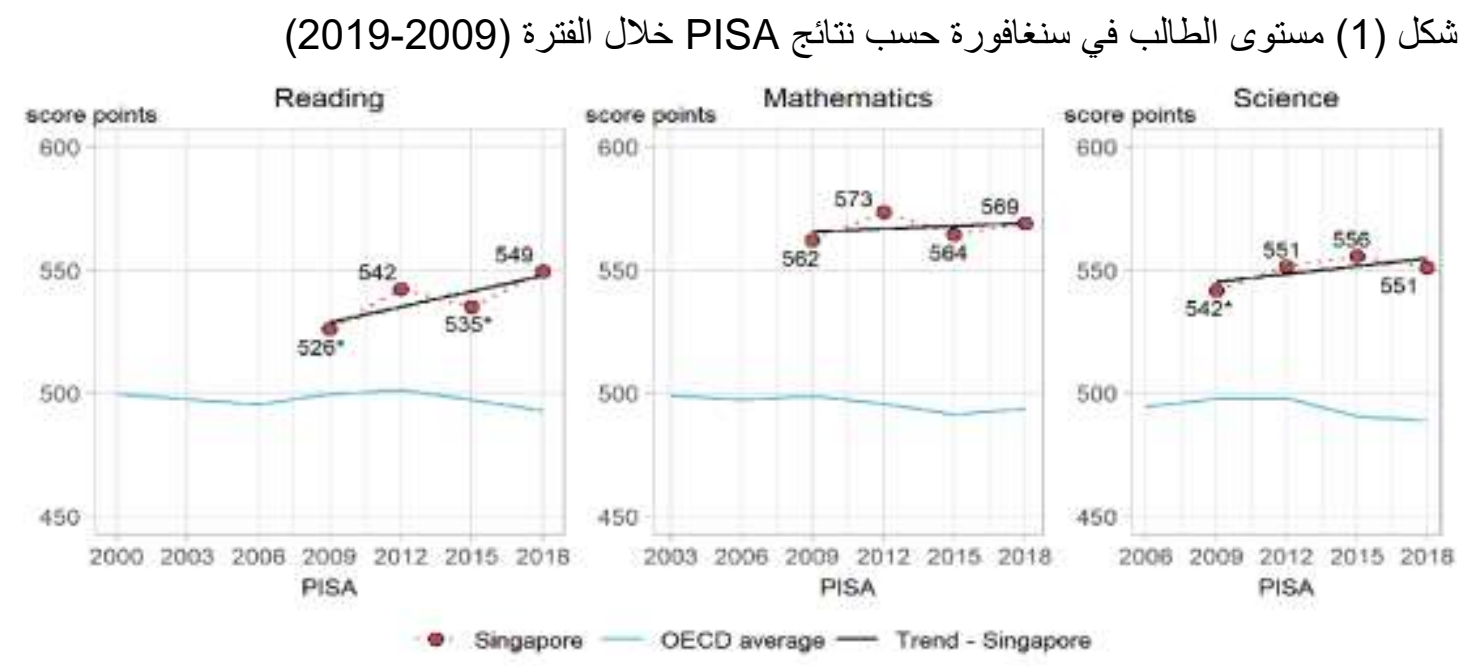

https://www. oecd. org/pisa

يتضح من الثكل أعلاه احتلال الطالب في سنغافورة الصدارة في الامتحان الدولي لتقييم الطلبة بل وأحرز نتائج أعلى من

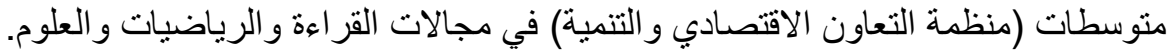

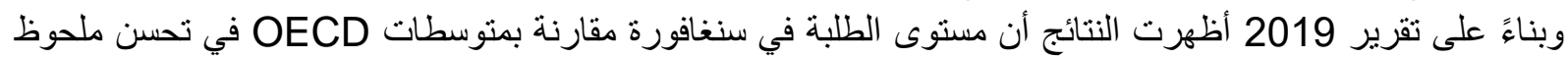
فيما يتعلق بالقر اعة و العلوم، على مدار الفترة الأطول (2009-2018) وبين (2015 و و 2018).

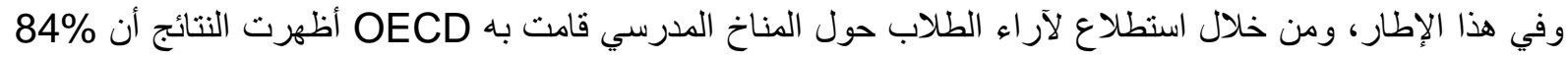

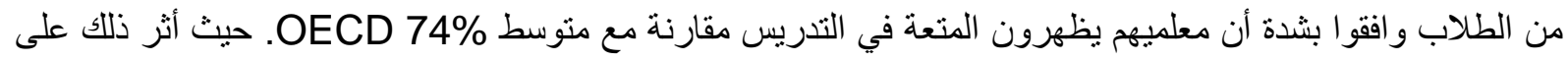

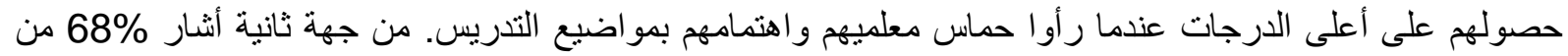

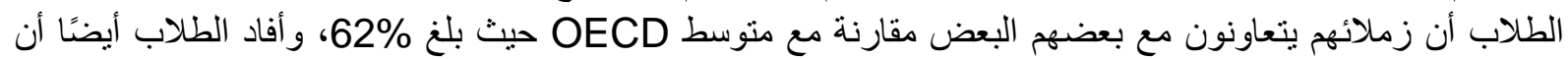
https://www. oecd. org/pisa

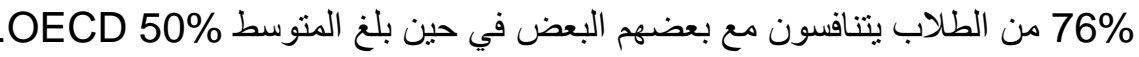

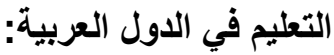

رصدت در اسة اخيرة ل PISA التحصيل العلمي من خلال مشاركة 79 دولة حول العام كان من ضمنها ست دول عربية

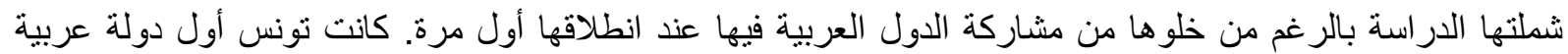

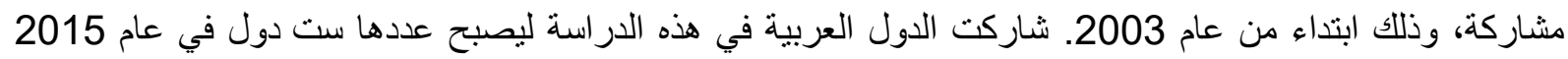

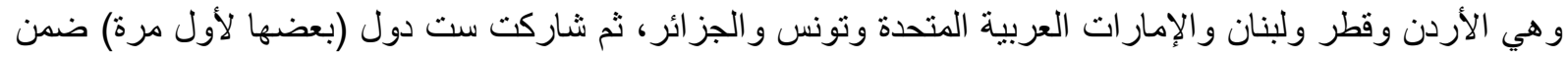

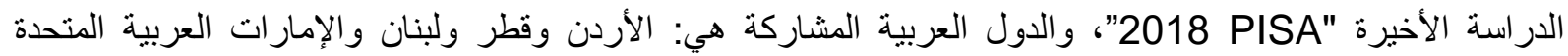

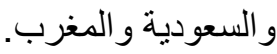
ويمكن تناول هذه المشار كات من خلال النقاط الاتية:

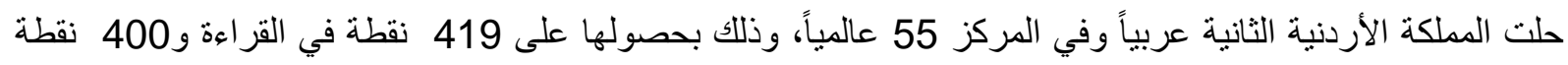

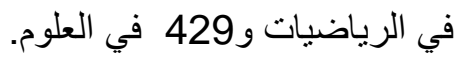
• جاءت قطر في المركز الثالث عربياً وفي المركز الستين عالمياً من ضمن قائمة الدول الـ 77 الـ 714 المشاركة، حيث حصل طلابها على 407 في القراءة 414 في الرياضيات و 419 في العلوم. 
ـ أما المملكة العربية السعودية، فحلت في المرتبة الر ابعة عربياً والمستوى 65 ع عالمياً بحصولها على 3969 نقطة في القر اءة و373 في الرياضيات و386 المبدة في العلوم.

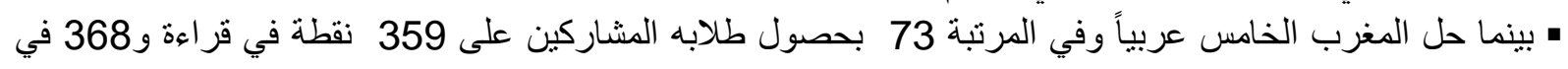

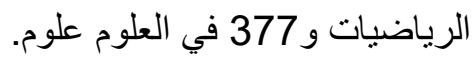

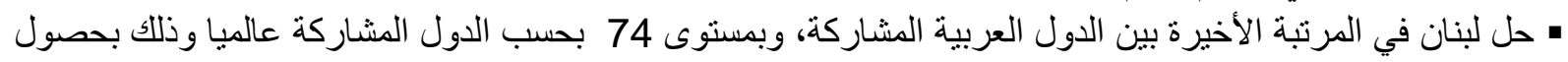

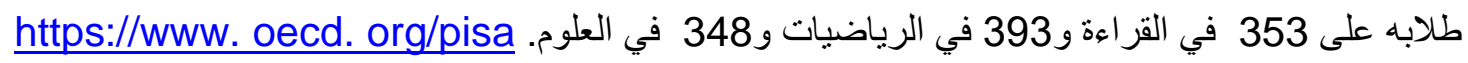

\section{الإنفاق العام على التعليم في سنغافورة:}

تفتقر سنغافورة اللى الأراضي والموارد الطبيعية فأصبح الإنسان أهم مواردها فكانت التحسينات والاستثمار ات في نظام

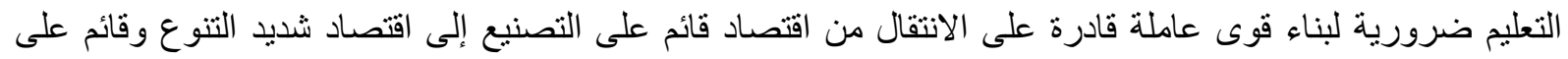

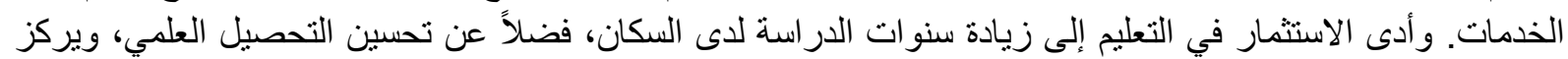

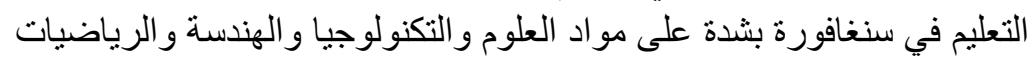

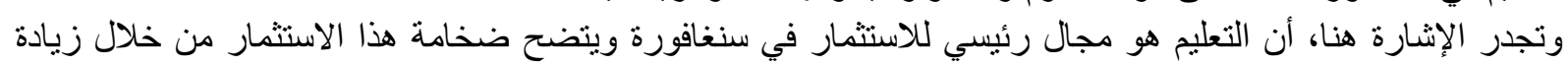

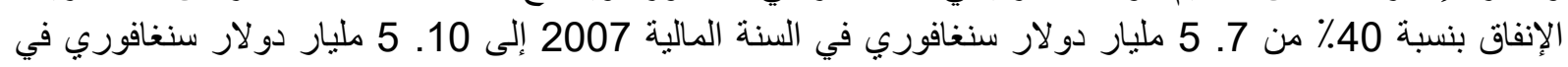

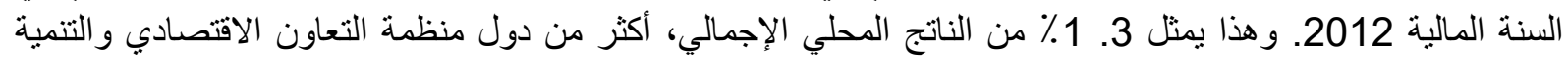

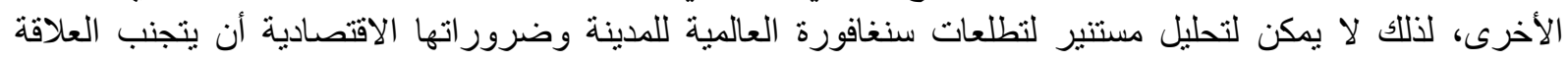

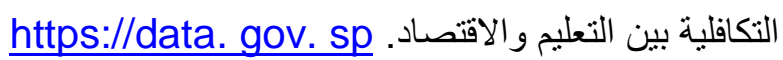

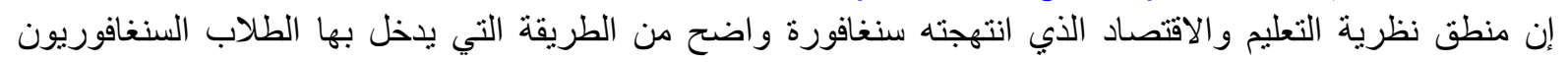

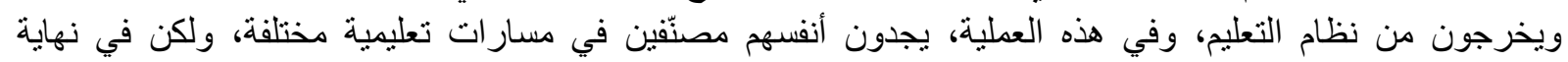

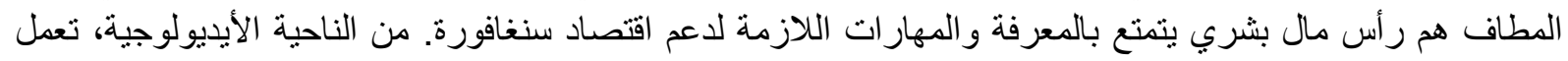

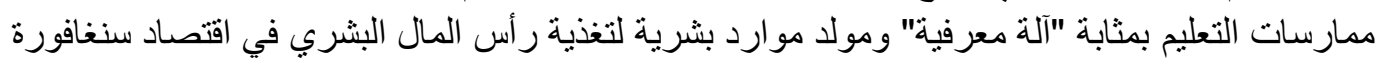
.(2014,Koh) ويمكن توضيح ذلك من خلال الجدول (1) و الذي يظهر زيادة الإنفاق الحكومي على التعليم ما بين الأعوام

(2019-1010) جدول (1) الانفاق الحكومي على التعليم

\begin{tabular}{|c|c|}
\hline Year & Recurrent Expenditure total (S \$ thousand) \\
\hline 2010 & $8,998,709$ \\
\hline 2011 & $9,697,793$ \\
\hline 2012 & $9,637,312$ \\
\hline 2013 & $10,664,868$ \\
\hline 2014 & $10,712,445$ \\
\hline 2015 & $11,235,741$ \\
\hline 2016 & $11,812,194$ \\
\hline 2017 & $12,079,538$ \\
\hline 2018 & $12,429,006$ \\
\hline 2019 & $12,039,000$ \\
\hline
\end{tabular}

https://data. gov. sg/dataset 


$$
\text { مقارنة حجم الإنفاق على التعليم مع بعض الدول: }
$$

من أجل توضيح الفرق بين سنغافورة وغيرها من الدول فيما يتعلق بالإنفاق العام على التعليم سيتم عمل مقارنة بين سنغافورة وبعض الدول الأجنبية والعربية وذللك على النحو الآتي: جدول (2) مقارنة بين سنغافورة وبعض الدول الأجنبية

\begin{tabular}{|c|c|c|c|c|c|}
\hline 2013 & 2012 & 2011 & 2010 & 2009 & الدولة /السنة \\
\hline 28.839 & $\begin{array}{l}31 . \\
372\end{array}$ & 28. 862 & 18.572 & 21.853 & سنغافورة \\
\hline 17. 269 & 17. 43 & 14. 957 & 15. 227 & 15. 64 & النرويج \\
\hline 17. 269 & 17. 43 & 14. 957 & 15. 227 & 15. 641 & سويسر ا \\
\hline- & - & 12. 219 & 12. 336 & 12. 48 & كندا \\
\hline 11.038 & $\begin{array}{c}12 . \\
797\end{array}$ & 11.919 & 11.945 & 11.843 & فنلندا \\
\hline 11.038 & $\begin{array}{l}11 . \\
035\end{array}$ & 10.665 & 10. 269 & 10. 186 & المانيا \\
\hline
\end{tabular}

https://data. worldbank. org/

من إعداد الباحثة استناداً على بيانات من البنك الدولي - يتضح من الجدول أعلاه وحسب المعلومات المنوفرة لأحدث قيمة في البنك الدولي أن سنغافورة في الصدارة فيما يتعلق التقال

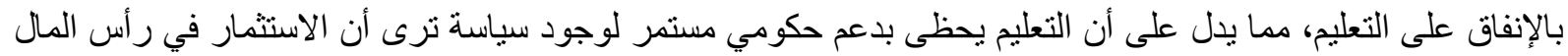

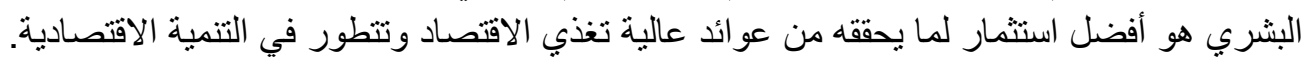

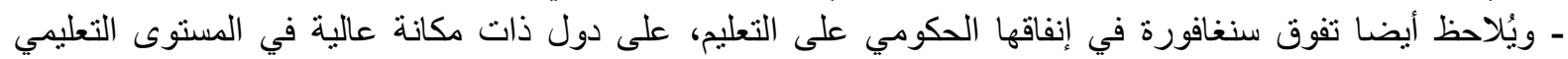
كفنلندا و ألمانيا وكندا في فترة وجيزة جدول (3) مقارنة بين سنغافورة وبعض الدول العربية

\begin{tabular}{|c|c|c|c|c|c|}
\hline 2013 & 2012 & 2011 & 2010 & 2009 & الدولة /السنة \\
\hline 28. 839 & 31.372 & 28. 862 & 18.572 & 21.853 & سنغافورة \\
\hline ---------- & 20. 99 & ---- & 24.847 & 25. 26 & تونس \\
\hline 13. 15 & 12. 31 & 13. 11 & 13. 82 & 14. 84 & قطر \\
\hline 7. 22 & -------- & -------- & --------- & ------- & الاردن \\
\hline 7. 22 & 8. 29 & ---------- & ------- & ------- & البحرين \\
\hline 8. 58 & 7.11 & 5.73 & 5.53 & 5.5 & لبنان \\
\hline
\end{tabular}

https://data. worldbank. org/

$$
\text { من إعداد الباحثة استناداً الى بيانات من البنك الدولي }
$$

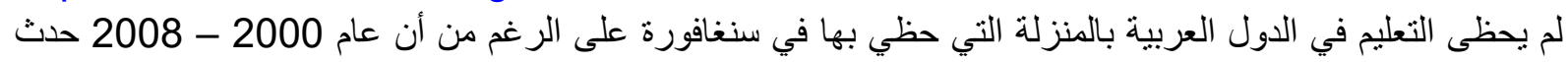

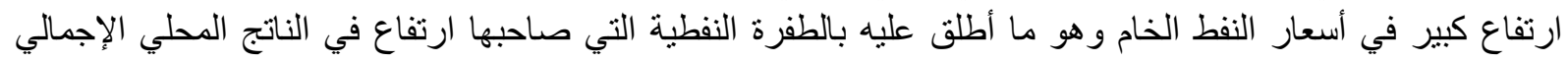

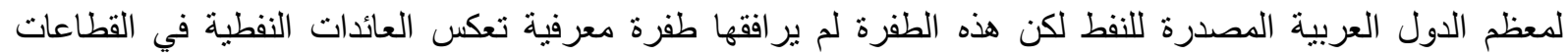
المعرفية (العادلي، 2013) 


\section{مساهمة القطاعات الاقتصادية في إجمالي الناتج المحلي لسنغافورة} في عام 2019 ساهم قطاع الصناعات التحويلية بنسبة 20. 9 \% 6 في الناتج المحلي الإجمالي لسنغافورة. في ذلك العام، بلغ الناتج المحلي الإجمالي بأسعار السوق الحالية 507. 6 مليار دو لار سنغافوري.

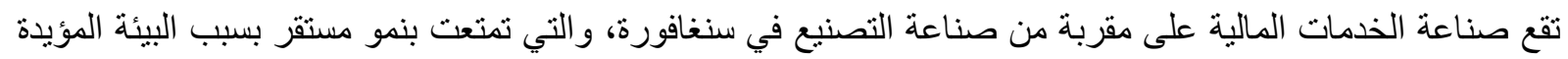
للأعمال في سنغافورة والاستقرار السياسي. موطن لأكثر من 200 بنك ومركز إقليمي مفضل للعديد من شركات فئات

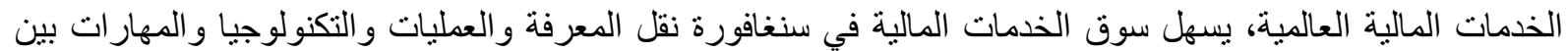

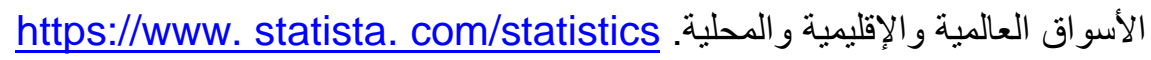
وفيما يلي توضيح لمدى مساهمة القطاعات المختلفة في إجمالي الناتج المحلي في سنغافورة 2019 شكل (2) مساهمة القطاعات الاقتصادية في إجمالي الناتج المحلي

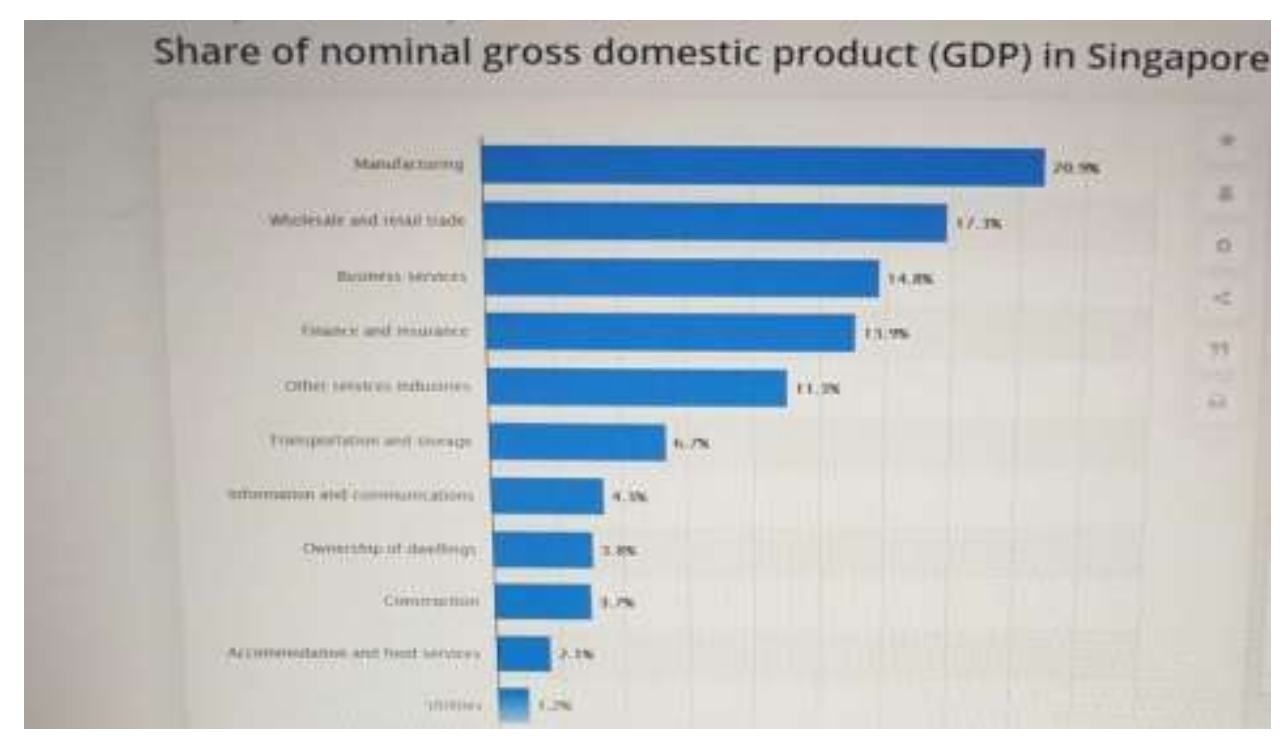

يُعتبر قطاع التصنيع أكبر صناعة في سنغافورة حتى الآن، حيث يساهم بنسبة 20٪ -25٪ من الناتج المحلي الإجمالي

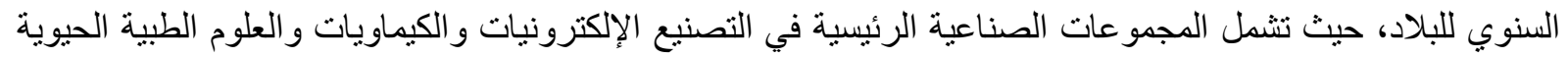

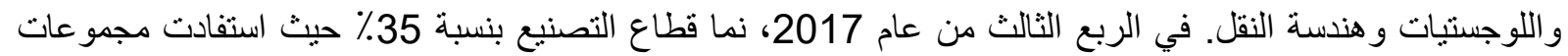
مثل الإلكترونيات و الهندسة الدقيقة من ارتفاع الطلب.

\section{خلاصة}

لقد ساهم الإنفاق العام على التعليم في التطور الاقتصادي في العديد من الدول التي كانت تعد من الدول النامية في منتصف

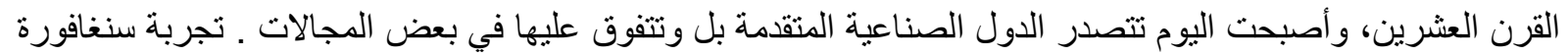

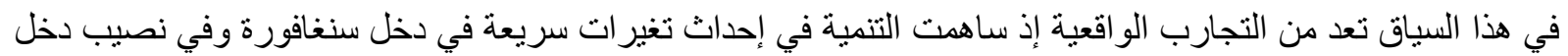

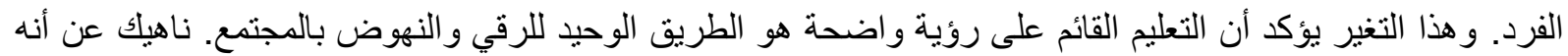

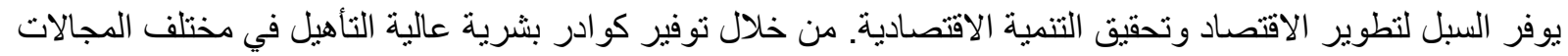

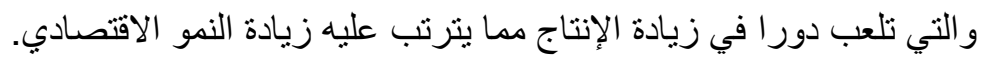

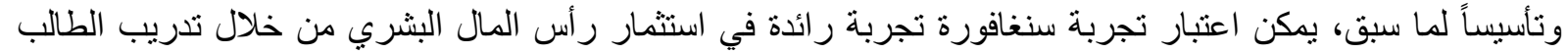

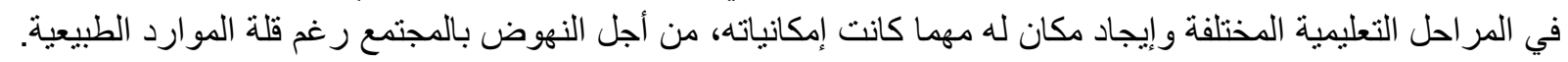

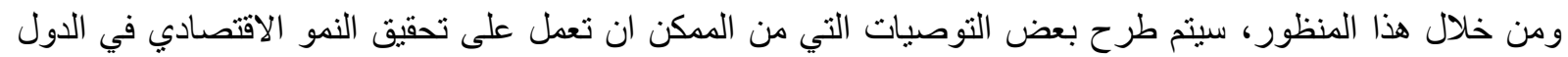

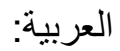

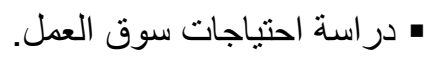

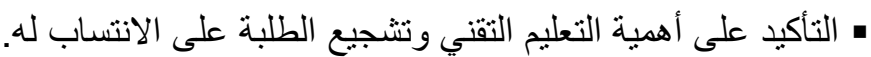

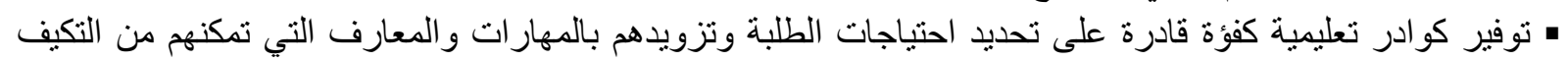
مع التغيرات المتسار عة. 
داود، عبد العزيز (2017). تحليل النظام التعليمي في جمهورية سنغافورة باستخدام نموذج مولهان النظري. مجلة التربية

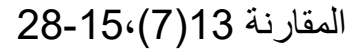

الرشدان، عبد الله (2001). في اقتصاديات التعليم. عمان: دار وائل للطباعة و النشر.

العارية، حسين (2012). دور التعليم في النمو الاقتصادي. المستقبل العربي (397) مركزئ (35) مركز دراسات الوحدة العربية،

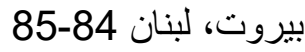

العادلي، عادل (2013). مساهمة التعليم في عملية الانماء الاقتصادي في البلدان العربية. مجلة كلية بغداد للعلوم الاقتصادية الجامعة، (35) 54-65.

Aaron Koh \& Terence Chong (2014) Education in the global city: the

manufacturing of education in Singapore, Discourse: Studies in the Cultural Politics of Education, Retrieved 28/5/2021

http://dx. doi. org/10. 1080/01596306. 2014. 931112

Hua, Yubo, "The Relationship between Public Expenditure on Education and Economic Growth: Evidence from China" (2016) Retrieved17/5/2021 https://tigerprints. clemson. edu/

Melissa Barnes \& Russell Cross (2018): 'Quality' at a cost: the politics of teacher education policy Critical Studies in Education, Retrieved 15/6/2021 https://doi. org/10.1080/17508487. 2018. 1558410

Mussagy, Ibraimo Hassane and Musibau Adetunji Babatunde (2015) "Government spending on education and economic growth in Mozambique: A cointegration approach". Retrieved 17/6/2021 from http://reid. ucm. ac. mz I

OECD (2019), PISA 2018 Results (Volume I): What Students Know and Can Do, PISA, OECD, Paris. Retrieved 12/6/2021from https://www. oecd. org/

Shafuda, Christover, De, Utpal (2020) governmental expenditure and human capital and growth. journal of economic structure. Retrieved 7/6/2021 from https://journalofeconomicstructures

Tan, C. , Koh, K. \& Choy, W. (2016). The education system in Singapore. Asian Education Systems (pp. 129-148). Retrieved 25/5/2021 from https://www. researchgate.

Wang,Ying and Shasha Liu (2016) "Education, Human Capital and Economic Growth: Empirical Research on 55 Countries and Regions (1960-2009)". Theoretical Economics Letters, Retrieved 20/6/2021 from

https://www. researchgate

https://worldtop20. org

https://www. statista. com

https://nces. cd. gov

https://www. oecd. org/pisa

https://data. gov. sp

https://data. gov. sg/dataset

https://data. worldbank. org 